\title{
QUAIS AS VANTAGENS DE TER UM SISTEMA BIMODAL (EAD E PRESENCIAL) DE ENSINO SUPERIOR: UMA PERSPECTIVA DOS DIRIGENTES DE IES.
}

\author{
CURITIBA/PR MAIO/2018
}

\author{
Angela Cristina Kochinski Tripoli \\ Karin Sell Schneider Lima \\ - UNINTER - Angela.t@uninter.com \\ Achiles Batista Ferreira Junior \\ - UNINTER - Karin.I@uninter.com \\ Daniel Weigert Cavagnari \\ - UNINTER - achiles.f@uninter.com \\ - UNINTER - daniel.ca@uninter.com
}

Tipo: Investigação Científica (IC)

Natureza: Relatório Final de Pesquisa

Categoria: Pesquisa e Avaliação

Setor Educacional: EDUCAÇÃO SUPERIOR

\begin{abstract}
RESUMO
A presente pesquisa analisou as vantagens de ofertar cursos em regime de bimodalidade, sendo estas Presencial e a distância (EAD), em Instituições de Ensino Superior. O estudo se desdobra em duas partes, pelo índice geral de cursos (IGC); e, na perspectiva do dirigente da instituição (Reitor ou Diretor), levando a pesquisa à quatro hipóteses. Os resultados apresentaram aspectos relacionados à mercado e à convergência educacional, bem como o mercado de EAD da próxima década será marcado sobretudo, pela inovação no processo educacional, nos modelos híbridos, com pouca distinção entre as modalidades, mas com a escolha do aluno da forma como quer estudar cada conteúdo. Na sequência para analisar se a modalidade impacta positivamente nos indicadores de qualidade, foi realizado o teste Qui-quadrado o qual indicou que existe diferença nos IGCs dos cursos Presenciais e Bimodais. Foi calculada a Vantagem Comparativa Revelada para os IGCs, os resultados aqui mostram que o Bimodal apresenta notas significativas em relação ao presencial, o que indica que as aferições de qualidade pelo IGC em IES bimodais, têm resultados melhores que em Instituições exclusivamente presenciais.
\end{abstract}

Palavras-chave: Bimodalidade; Ensino Presencial e a Distância; Ensino híbrido; Futuro da Educação Superior. 


\section{INTRODUÇÃO}

As primeiras formas de implantação da educação a distância em IES, utilizavam materiais impressos, posteriormente, evoluíram para o uso de videoconferência com o apoio de ambientes virtuais de aprendizagem, mas ainda, preservando características de presencialidade. Ao longo dos últimos 5 anos, a EAD no Brasil vem utilizando com mais frequência os recursos tecnológicos através de ambientes virtuais de aprendizagem e modelos pedagógicos com interfaces interacionistas, o que demonstra uma adaptação relativa às novas tecnologias aplicadas à educação, as quais alteraram o modo como aprendemos, o processo de ensino e aprendizagem tornou-se uma espécie de "inteligência coletiva", termo cunhado pelo francês Pierre Lévy (LÉVY, 2011).

O presente trabalho tem como objetivo analisar as vantagens de ofertar cursos em regime de bimodalidade, sendo estas Presencial e a distância (EAD), nas Instituições de Ensino Superior, na visão do dirigente da instituição (Reitor ou Diretor). Pretende-se mapear aspectos que sinalizem a visão de futuro de reitores ou dirigentes sobre a oferta de EAD como elemento de sobrevivência mercadológica para instituições de educação superior, além disso, foram levantados resultados IDD, para analisar se há impacto na qualidade aferida por conta da escolha pela bimodalidade.

\section{METODOLOGIA}

Para compor o objetivo do presente estudo, foram elencadas as seguintes hipóteses de pesquisa:

- H1: A bimodalidade traz vantagens relevantes e melhoria de qualidade no processo de ensino aprendizagem como um todo;

- H2: a bimodalidade apresenta benefícios limitados à educação, ligados apenas à aspectos do uso materiais didáticos e ambientes virtuais de aprendizagem;

- H3: ofertar cursos em bimodalidade é uma questão obrigatória para a sobrevivência das IES nos próximos 10 anos.

- H4: a bimodalidade impacta positivamente nos indicadores de qualidade;

A presente pesquisa pauta-se em diferentes procedimentos metodológicos tanto qualitativo quanto qualitativo, na medida em que se utiliza de escalas e técnicas distintas de análise, utilizando dados secundários e de procedimentos matemáticos e estatísticos para medir a qualidade dos cursos de graduação no país, com o levantamento de dados em sites especializados e na base de dados do INEP, para mapeamento das IES 
brasileiras que ofertam cursos Presenciais e $\mathrm{E}$

Para o mapeamento de vantagens e desvantagens da modalidade de Ensino a distância, foi utilizado por meio de entrevistas semiestruturada por e-mail com reitores e dirigentes de IES, em regime de bimodalidade. Para a entrevista, foi utilizado um roteiro semiestruturado de perguntas: 1.Cargo na IES (descreva brevemente suas principais atribuições) 2. A IES atual opera com ensino presencial e a distância? 3.Tempo de experiência na gestão de IES (em sua carreira, não apenas na IES atual) 4.Em sua opinião, quais as vantagens em uma IES ofertar cursos em ambas as modalidades? 5 . A EAD impacta em algum aspecto na modalidade presencial? 6. Como você entende o mercado de educação superior daqui a 10 anos? Qual o impacto da bimodalidade nesse contexto? 7. Algum outro aspecto que gostaria de mencionar?

Foram consideradas as IES bimodais aquelas que possuem credenciamento tanto para a modalidade a distância quanto para a presencial, selecionaremos dois grupos, um de IES exclusivamente credenciadas para a modalidade presencial e outro com IES bimodais. Ao total foram enviadas 40 solicitações de entrevista para endereços obtidos através de sites das IES, rede social Linkedin e indicações de dirigentes. Essa ação resultou no retorno de 20 pautas respondidas e 17 selecionadas para o estudo de acordo com os seguintes critérios, (a) dirigente que faça gestão de uma IES que oferta cursos tanto em regime presencial quanto a distância; (b) dirigente estar em um cargo de gestão que tenha poder decisório para as duas modalidades de ensino: presencial e EAD;

\section{REFERENCIAL TEÓRICO}

Segundo dados do INEP (2016), atualmente cerca de 3 milhões de estudantes brasileiros cursam uma graduação a distância, sendo 2,5 milhões em instituições privadas. Comparado aos dados de 2005, levantados pela ABRAEAD, o crescimento da EAD se mostra exponencial, indo de 309.957 matriculados aos 3 milhões em 2015.

\subsection{Panorama da Educação Superior Bimodal no Brasil.}

Se analisarmos que o crescimento da EAD foi de 309.957 matriculados aos 3 milhões em 2015, um crescimento de cerca de $900 \%$ em doze anos. Comparado aos dados do balanço social da SESU (2015), realizado em toda a educação superior, independente da modalidade, as matrículas na educação superior brasileira cresceram de 3,9 milhões em 2003 para 7,3 milhões em 2013, percebe-se que a expansão da EAD, foi maior em números relativos, mas em quantidade real, os números ainda são menores que os da 
educação presencial. Das 2768 IES brasileiras, apenas 391 (14\%) são credenciadas para atuar nas duas modalidades de ensino, sendo elas: presencial e a distância (EaD).

\subsection{A perspectiva dos índices avaliadores propostos pelo INEP}

Segundo Dias Sobrinho (2010, p. 195, in Hoffmann et al, 2014): a avaliação de instituições de ensino superior, é uma forma de controle de qualidade e melhoria de eficiência, sendo capaz de promover melhorias curriculares, nas metodologias de ensino e aprendizagem, na gestão educacional e institucional, nas políticas e configurações do sistema educacional. O Sistema Nacional de Avaliação da Educação Superior (SINAES), instituído pelo MEC em 2004, por meio da Lei no 10.861 , consiste em um sistema de avaliação institucional amplo que contempla pilares como a auto avaliação, avaliação externa, condições de ensino e instrumentos de informação como censo da educação superior e cadastro preenchido pela IES (HOFFMANN et al, 2014).

Os indicadores do SINAES, considerados medidas da qualidade da Educação Superior, são: o Conceito Preliminar de Curso (CPC), Índice Geral de Cursos (IGC), que formam a base informacional para os processos de avaliação in loco e resultam nos: Conceitos de Curso (CC) e Conceito Institucional (CI) (INEP, 2011). Muitas polêmicas estão relacionadas aos indicadores, porém, esse estudo isenta-se desse campo de discussão.

De acordo com o INEP (2017), "o Índice Geral de Cursos Avaliados da Instituição (IGC) é um indicador de qualidade que avalia as Instituições de Educação Superior". Ainda segundo o Inep, o IGC depende fortemente da média do CPC (Conceito Preliminar de Cursos), e é composto "pela média dos CPCs do último triênio, relativos aos cursos avaliados da instituição, ponderada pelo número de matrículas em cada um dos cursos computados"

\section{APRESENTAÇÃo E ANÁLISE dOS RESULTADOS}

As entrevistas foram realizadas com Reitores e/ou dirigentes de Instituições de Ensino Superior que operam com as duas modalidades: Presencial e EAD. Foram enviados 40 e-mails com a solicitação de entrevista, destes, obteve-se um retorno de 20 respondentes, mas três deles foram eliminados por não se enquadrarem no perfil de reitor ou dirigente de IES, ambos coordenavam apenas os cursos na modalidade EAD, e para evitar viés na pesquisa, foram excluídos da amostra. Foram aceitas respostas de 27 de novembro à 04 de dezembro de 2017. Dos 17 entrevistados, 15 possuem mais de 10 anos de experiência e 2 de 5 a 10 anos, o que caracteriza uma boa visão do contexto educacional. Na Tabela 1, é apresentado um resumo da categoria administrativa da IES 
e dos respectivos cargos dos respondentes.

Tabela 1: Categoria Administrativa da IES e Cargo dos Respondentes

$\begin{array}{lll}\text { ENTREVISTADO (A) } & \text { CAT. ADM DA IES } & \text { CARGO NA IES } \\ 1 & \text { UNIVERSIDADE } & \text { Pró-Reitora } \\ 2 & \text { UNIVERSIDADE } & \text { Diretor } \\ 3 & \text { FACULDADE } & \text { Diretor } \\ 4 & \text { CENTRO UNIVERSITÁRIO } & \text { Reitor } \\ 5 & \text { UNIVERSIDADE } & \text { Gerente } \\ 6 & \text { UNIVERSIDADE } & \text { Pró-Reitor } \\ 7 & \text { UNIVERSIDADE } & \text { Gerente de Ensino } \\ 8 & \text { CENTRO UNIVERSITÁRIO } & \text { Diretor } \\ 9 & \text { CENTRO UNIVERSITÁRIO } & \text { Diretor } \\ 10 & \text { FACULDADE } & \text { Coordenador Geral } \\ 11 & \text { UNIVERSIDADE } & \text { Reitor } \\ 12 & \text { UNIVERSIDADE } & \text { Diretor } \\ 13 & \text { CENTRO UNIVERSITÁRIO } & \text { Diretor } \\ 14 & \text { CENTRO UNIVERSITÁRIO } & \text { Diretor } \\ 15 & \text { CENTRO UNIVERSITÁRIO } & \text { Reitor } \\ 16 & \text { CENTRO UNIVERSITÁRIO } & \text { Assessoria da Reitoria } \\ 17 & \text { FACULDADE } & \text { Diretor }\end{array}$

Para organizar a análise e a exposição de resultados, foi desenvolvida a categorias de análise: Vantagens de se operar em regime de bimodalidade, e como elementos derivativos dessa categoria: a) Impactos da EAD no PSC e b) O mercado de educação na próxima década. Os resultados foram catalogados como Aspectos Pedagógicos, informações ligadas ao processo de ensino-aprendizagem e Aspectos Mercadológicos, relacionados ao mercado de educação superior e gestão administrativa.

Na categoria analítica "Vantagens de se operar em regime de bimodalidade": além dos dados da entrevista, para essa categoria e como pano de fundo para a pesquisa, foram levantados do site do INEP (2017), os resultados de IDD das IES brasileiras credenciadas para EAD e presencial. Esse dado trouxe respostas para a H4: a bimodalidade impacta positivamente nos indicadores de qualidade;

Nos elementos derivados "Visão de futuro com ou sem oferta de EAD" e Impactos da EAD no Presencial", foram relacionadas as hipóteses H1, H2 e H3; 
Quanto às vantagens na oferta bimodal, os respondentes apontaram quanto aos aspectos de mercadológicos, a ampliação da abrangência geográfica e da base de alunos, otimização de recursos, sendo estes, custos operacionais, corpo docente e técnicos administrativos. De acordo com Mill (2006) a gestão das IES que possuem $E A D$, o gestor cuida da estruturação das instalações, equipes de trabalho, redes comunicativas, financiamento, infraestrutura física e tecnológica, além das diversas e imprescindíveis questões pedagógicas envolvidas no ensino-aprendizagem da EaD.

Quanto aos aspectos educacionais e pedagógicos, foram indicadas questões relacionadas à convergência digital, de acordo com ABEGG e BASTOS (2016), a convergência digital que promove o aprendizado colaborativo, é uma tendência natural para a educação no futuro.

Quando instados a responder sobre os impactos de uma modalidade em outra, todos os respondentes foram unânimes em afirmar que a Ead impacta sobremaneira a modalidade presencial, mais pedagogicamente do que mercadologicamente, nesse, foi citada a redução da procura para o ensino presencial, mas a otimização de recursos foi pouco mencionada, talvez pelo ensino presencial ter custos próprios para a sua operação que independem da modalidade EAD.

Já nos aspectos relacionados ao processo de ensino aprendizagem, os respondentes indicaram o fenômeno da convergência educacional como uma tendência, por meio dos modelos híbridos e do blended learning, além da incorporação de recursos pedagógicos criados para a EAD, como material didático, vídeo-aulas, exercícios, etc. A cultura de controle e organização embutida nos modelos educacionais a distância, também foram mencionados como elementos influenciadores da cultura organizacional e pedagógica da IES.

As questões relacionadas ao mercado educacional da próxima década apresentaram respostas bem similares aos impactos de uma modalidade em outra, porém, os aspectos mercadológicos receberam mais destaque na perspectiva dos entrevistados. Segundo esses resultados, o mercado de EAD da próxima década será marcado sobretudo, pela inovação no processo educacional, nos modelos híbridos, com pouca distinção entre as modalidades, mas com a escolha do aluno da forma como quer estudar cada conteúdo.

Segundo Castells (1999), "as tecnologias da informação, junto com a habilidade para usá-las e adaptá-las, são o fator crítico para gerar e possibilitar acesso à riqueza, poder e conhecimento no nosso tempo". Canalizar esse fator para a evolução na educação, é 
um desafio das instituições, aplicando mudanças e a inovação por meio de seus modelos pedagógicos, ambientes virtuais e espaços colaborativos de aprendizagem.

Levy (2003) afirma que o sucesso de um curso, seja EAD, presencial ou híbrido, depende de uma reavaliação geral por todos os envolvidos: gestores, docentes, alunos, conselhos, etc. É preciso rever modelos, currículos, os serviços aos estudantes, a capacitação da equipe de atendimento aos estudantes. Esse mesmo autor ainda afirma que a missão e visão da instituição, sejam impregnadas por uma cultura de inovação e mudança.

Com relação à $\mathrm{H} 4$, onde buscava-se verificar se, a bimodalidade impacta positivamente nos indicadores de qualidade, foi utilizado o teste Qui-quadrado, o qual, com base em uma tabela de contingências, testa a similaridade de proporções em uma amostra. É feita uma análise bivariada com duas categorias do ICG, o qual usa como base uma média dos conceitos de curso de graduação da instituição, ponderada a partir do número de matrículas, mais notas de pós-graduação de cada instituição de ensino superior. $\mathrm{Na}$ análise bivariada, analisa-se a relação entre duas variáveis qualitativas independentes, cada uma com duas ou mais categorias. As tabelas de contingência são utilizadas para estudar a relação entre duas ou mais variáveis categóricas, descrevendo a frequência das categorias de uma das variáveis, relativo à outra categoria.

Foram analisadas 2.143 instituições de ensino superior do país, sendo que 1.756 oferecem o ensino presencial e 387 oferecem ensino EAD e presencial (bimodal), conforme Tabela 02.

Tabela 02: IES presenciais e bimodais por nota de IGC.

$\begin{array}{llll}\text { IGC } & \text { ENSINO } & \text { ENSINO } & \text { TOTAL } \\ & \text { PRESENCIAL } & \text { EAD/PRESENCIAL } & \\ & & \text { (BIMODAL) } & \\ 1 & 11 & 0 & 11 \\ 2 & 325 & 9 & 334 \\ 3 & 1185 & 239 & 1424 \\ 4 & 224 & 122 & 346 \\ 5 & 11 & 17 & 28\end{array}$

$\begin{array}{lll}\text { TOTAL } 1756 & 387 & 2143\end{array}$ 
TABELA 03: PORCENTAGENS (COLUNAS)

$\begin{array}{lll}\text { IGC } & \text { PRESENCIAL } & \begin{array}{l}\text { EAD/PRESENCIAL } \\ \text { (BIMODAL) }\end{array} \\ 1 & 0,6 \% & 0,0 \% \\ 2 & 18,5 \% & 2,3 \% \\ 3 & 67,5 \% & 61,8 \% \\ 4 & 12,8 \% & 31,5 \% \\ 5 & 0,6 \% & 4,4 \% \\ \text { TOTAL } 100,0 \% & 100,0 \%\end{array}$

TABELA 03: PORCENTAGENS (LINHAS)

$\begin{array}{lll}\text { IGC } & \text { PRESENCIAL } & \begin{array}{l}\text { EAD/PRESENCIAL } \\ \text { (BIMODAL) }\end{array} \\ 1 & 100,0 \% & 0,0 \% \\ 2 & 97,3 \% & 2,7 \% \\ 3 & 83,2 \% & 16,8 \% \\ 4 & 64,7 \% & 35,3 \% \\ 5 & 39,3 \% & 60,7 \%\end{array}$

Devido ao valor do Qui quadrado ser de 0,000, indica que existe diferença nos IGCs dos cursos Presenciais e Bimodais. Para as IES que ofertam somente o ensino presencial os IGCs com notas 3, 4 e 5 obtiveram um percentual de $80,9 \%$, sendo $67,5 \%$ para nota $3,12,8 \%$ para nota 4 e $0,6 \%$ para a nota 5 . As instituições que ofertam o ensino tanto presencial quanto a distância obtiveram nas notas 3, 4 e 5 um percentual de $97,7 \%$, sendo $61,8 \%$ para a nota $3,31,5 \%$ para a nota 4 e $4,4 \%$ para a nota 5 . Sintetizando esses resultados, chegamos a um índice médio geral (todas as notas) ponderado dessas notas para o Presencial de 2,94 e para o Bimodal de 3,38. Ou seja, dado esse índice médio ponderado, comprovadamente o Bimodal apresenta um peso maior nas notas significativas em relação ao presencial.

Portanto, baseado nos resultados do teste Qui-quadrado, podemos considerar que as Instituições de Ensino que possuem ensino a distância, possuem resultados melhores nas aferições de qualidade pelo IGC em relação as que não ofertam EAD.

\section{CONCLUSÃO}

O presente trabalho teve como objetivo analisar as vantagens de ofertar cursos em 
regime de bimodalidade, sendo estas Presencial e a distância (EAD), em Instituições de Ensino Superior, na perspectiva do dirigente da instituição (Reitor ou Diretor). Foram elencadas quatro hipóteses de pesquisa, a saber: $\mathrm{H} 1$ ) a bimodalidade traz vantagens relevantes e melhoria de qualidade no processo de ensino aprendizagem como um todo. H2) a bimodalidade apresenta benefícios limitados à educação, ligados apenas à aspectos do uso materiais didáticos e ambientes virtuais de aprendizagem. Com relação a essas duas questões de pesquisa, o resultado apresentou aspectos relacionados à mercado (Aspectos mercadológicos) e à convergência educacional (Aspectos Pedagógicos). Quanto aos aspectos de mercado, foram apontados a ampliação da abrangência geográfica e da base de alunos, otimização de recursos, sendo estes, custos operacionais, corpo docente e técnicos administrativos. Quanto aos aspectos educacionais e pedagógicos, foram indicadas questões relacionadas à convergência digital, por meio dos modelos híbridos e do blended learning, além da cultura de controle presente na EAD e da incorporação de recursos pedagógicos criados para a modalidade a distância, como material didático, vídeo-aulas, exercícios, etc.

$\mathrm{Na}$ questão H3 sobre o fato de que ofertar cursos em bimodalidade é uma questão obrigatória para a sobrevivência das IES nos próximos 10 anos, apresentaram respostas bem similares aos impactos de uma modalidade em outra, porém, os aspectos mercadológicos receberam mais destaque na perspectiva dos entrevistados. Segundo esses resultados, o mercado de EAD da próxima década será marcado sobretudo, pela inovação no processo educacional, nos modelos híbridos, com pouca distinção entre as modalidades, mas com a escolha do aluno da forma como quer estudar cada conteúdo.

Com relação à $\mathrm{H} 4$, onde buscava-se verificar se, a bimodalidade impacta positivamente nos indicadores de qualidade, o valor do Qui quadrado indicou 0,000 , o que significa que existe diferença nos IGCs dos cursos Presenciais e Bimodais. Sintetizando esses resultados, chegou-se a um índice médio geral (todas as notas) ponderado dessas notas para o Presencial de 2,94 e para o Bimodal de 3,38. Ou seja, dado esse índice médio ponderado, comprovadamente 0 Bimodal apresenta um peso maior nas notas significativas em relação ao presencial, o que indica que as aferições de qualidade pelo IGC em IES bimodais, têm resultados melhores que em Instituições exclusivamente presenciais.

\section{REFERÊNCIAS BIBLIOGRÁFICAS}

ABEGG, Ilse; DE BASTOS, Fábio da Purificação. Convergência e integração de tecnologias criativas em ambientes virtuais. ETD - Educação Temática Digital, Campinas, SP, v. 18, n. 1, p. 60-70, abr. 2016. 
CASTELLS, M. Sociedade em rede: a era da informação; economia, sociedade e cultura. São Paulo: Paz e Terra, 1999.

Hoffmann, Celina; Zanini, Roselaine Ruviaro; Corrêa, Ângela Cristina; Siluk, Julio Cezar; Schuch Júnior, Mairesse Vitor Francisco; Ávila, Lucas Veiga. O desempenho das universidades brasileiras na perspectiva do Índice Geral de Cursos (IGC). Educ. Pesqui., São Paulo, v. 40, n. 3, p. 651-666, jul./set. 2014.

INEP - Instituto Nacional de Estudos e Pesquisas Educacionais Anísio Teixeira. Disponível em http://www.inep.gov.br/. Acessado em julho de 2017.

LÉVY, P. A inteligência coletiva: por uma antropologia do ciberespaço. São Paulo: Loyola; 2011.

LEVY, S. Six factors to consider when planning online distance learning programs in higher education. Online Journal of Distance Learning Administration, v. 6, n. 1, Spring 2003.

MEC - Ministério da Educação. Disponível em https://www.mec.gov.br/. Acessado em julho de 2017.

MILL, D. Educação a distância e trabalho docente virtual: sobre tecnologia, espaços, tempos, coletividade e relações sociais de sexo na Idade Mídia. 2006. 322f. Tese (Doutorado em Educação)- Faculdade de Educação, Universidade Federal de Minas Gerais, Belo Horizonte, 2006.

SEMESP- Sindicato das Mantenedoras de Ensino Superior. Disponível em http://www.semesp.org.br/site/. Acessado em julho de 2017. 